\title{
O tempo e a concepção de realidade sob a abordagem cognitivista
}

\author{
Melissa Giovana LAZZARI @ \\ Universidade Federal do Rio Grande do Sul (UFRGS)
}

\section{RESUMO}

A presente resenha parte da fala da $\operatorname{Prof}^{\mathrm{a}} \mathrm{Dr}^{\mathrm{a}}$ Jussara Abraçado (UFF/CNPq) intitulada Abordagem cognitivista do tempo: o tempo e a concepção da realidade, proferida no dia 09 de julho de 2020 para o evento Abralin ao Vivo - Linguists Online. À luz de noções teóricas provenientes da Gramática Cognitiva de Langacker (1991), a conferencista parte da relação existente entre o tempo e a conceptualização da realidade, tendo em vista que as predicações temporais são responsáveis por ordenar a situação conceptualizada em um dado momento da realidade. Toda a explicitação da conferencista parte do português brasileiro, de forma que outras línguas não são abordadas, cabe destacar que a concepção de tempo apre-

OPEN ACCESS

EDITADO POR Raquel Freitag

AVALIADO POR Marcos Wiedemer sentada tem por base a concepção ocidental de tempo.

\section{ABSTRACT}

This text reviews the speech of Prof ${ }^{\mathrm{a}} \mathrm{Dr}^{\mathrm{a}}$ Jussara Abraçado (UFF/CNPq) entitled Cognitive approach to time: time and the conception of reality that took place in July 9, 2020 during Abralin ao Vivo - Linguists Online. By using theoretical notions from Langacker's Cognitive Grammar (1991), the lecturer starts from the relationship between time and the conceptualization of reality, considering that temporal predictions are responsible for ordering the conceptualized situation at a given moment in reality. All of her explanation is based on Brazilian Portuguese, so that other languages are not addressed. It is worth noting that the concept of time presented is based on the Western concept of time. 


\section{REVISTA DA ABRALIN}

PALAVRAS-CHAVE

Tempo. Realidade. Cognitivismo.

\section{KEYWORDS}

Time. Reality. Cognitivism.

A conferência aqui resenhada aborda a relação entre tempo e realidade e foi proferida pela Prof. ${ }^{a}$ Dr. ${ }^{a}$ Jussara Abraçado sob o título Abordagem cognitivista do tempo: o tempo e a concepção da realidade como parte do evento Abralin ao Vivo - Linguists Online, iniciativa da Associação Brasileira de Linguística. A referida pesquisadora é professora titular de Linguística da Universidade Federal Fluminense e desenvolve pesquisas, sobretudo, na área de interface entre linguística cognitiva e sociolinguística, além de atuar nas seguintes temáticas: modalidade e tempo, (inter)subjetividade e ordem das palavras.

O aparato teórico do qual a pesquisadora se lança para configurar tal fala é composto por três obras de referência: O tempo, o tempo linguístico e o tempo verbal (Abraçado, 2020), Foundations of Cognitive Grammar (Langacker, 1991) e O Significado na Linguagem e na Mente: Uma Introdução à semântica (Soares da Silva, no prelo).

O primeiro tópico apresentado pela conferencista é o de conceptualização. Tal conceito se descreve como um processo de apreensão da realidade ou de uma dada entidade que vem a ser objeto de conceptualização por um determinado o sujeito conceptualizador. Em seguida, Abraçado apresenta a definição de sujeito(s) conceptualizador(es). Em linhas gerais, pode se dizer que o sujeito conceptualizador é o locutor envolvido no ato comunicativo, haja vista que esta abordagem parte de um centro dêitico (o aqui, o agora, o hoje). Pelo viés da Linguística Cognitiva, usado pela autora, a conceptualização é encarada como simbolização das experiências cotidianas através de estruturas gramaticais e de palavras disponíveis no léxico, tendo isso em vista, o que é falado por alguém não representa o mundo, mas a visão que esse alguém tem do mundo.

A concepção de tempo parte do constructo ocidental que permeia esse conceito: atrás de nós, por convenção, há o que denominamos passado, enquanto o que está à frente é denominado futuro, o que vivemos no momento de enunciação, onde nos situamos, é o presente. Para ilustrar como a conceptualização do tempo se traduz no uso cotidiano, Abraçado expõe uma série de exemplos em língua portuguesa oriundos de postagens de redes sociais, contribuindo para aproximação entre a teoria e o uso da linguagem. Vale ressaltar que a autora menciona que, em outras línguas, a conceptualização de tempo opera de maneira diferente.

No tocante ao tempo linguístico, cabe destacar que esse é responsável por localizar uma situação no eixo horizontal em que se inscreve a noção de tempo em relação ao próprio tempo ou a uma situação, sendo relativo ao tempo de fala ou a um momento construído discursivamente. Tomando sob outra perspectiva: a localização se dá a partir do tempo do ato de fala ou de um momento marcado no discurso e pode ser expressa no discurso por meio de flexões verbais ou expressões 


\section{REVISTA DA ABRALIN}

adverbiais. Na fala da conferencista, é apresentada uma série de exemplos de notícias e matérias jornalísticas. Cabe destacar o que diz Soares da Silva (no prelo) com relação aos tempos linguísticos: esses não exprimem apenas noção de tempo, mas também de modalidade e de aspectualidade, além de informação discursiva.

Na sequência, Abraçado aborda o tempo dêitico, que se caracteriza por sinalizar intervalos de tempo simultâneos, posteriores ou anteriores ao tempo do ato de fala. Tal conceito está em oposição ao tempo anafórico, no qual há um ponto de referência discursivamente estabelecido, de forma que relações de anterioridade, posterioridade e simultaneidade são as mesmas. Os referidos conceitos são ilustrados pela conferencista através de exemplos retirados de jornais.

Tendo visto a noção de tempo, a pesquisadora passa a abordar a conceptualização da realidade ao propor a seguinte questão: Ao localizarmos um evento ou situação no eixo temporal, estabelecemos um estatuto em relação à realidade. Mas como conceptualizamos a realidade? A fim de responder tal questionamento, Abraçado traz para a discussão a concepção de Langacker (1991), para quem a realidade é dependente das pessoas, não uma realidade objetiva como muitos creem. Tal estatuto se dá ao passo que sempre quando falamos de uma situação ou acontecimento, podemos considerá-los como pertencentes ou não à realidade. Segundo o autor, depende do sujeito conceptualizador reconhecer tal situação como parte da sequência evolutiva do mundo, concedendo sentido de irrealidade ou realidade. Entretanto, cabe destacar que, conforme cita Abraçado, Langacker também afirma ser possível propor que exista um grau de concepções comuns de realidade, haja vista que parte do nosso conhecimento de mundo é comum à espécie humana. A conferencista afirma que é possível efetuar também uma avaliação epistemológica, já que podemos, enquanto seres humanos, avaliar o que é (im)possível levando em consideração a nossa concepção de realidade. Em consonância com essa ideia, Abraçado apresentou o modelo evolutivo dinâmico da realidade (Langacker, 1991) e o exemplificou através de notícias de diferentes jornais. Em tal modelo, situações de que não temos ciência ou que existam apenas no nosso imaginário estão no campo da irrealidade tanto quanto aquelas que podemos prever com algum nível de segurança estão para a realidade projetada. Além disso, estão no campo da realidade potencial situações que julgamos apenas como possíveis. No tocante à diferença entre as realidades projetada e a potencial, Abraçado afirma que a fronteira entre ambas é imprecisa; contudo, ela pode ser sinalizada através do uso de determinadas formas linguísticas.

No quadro abaixo, são expostas as ideias da conferencista acerca do estatuto de realidade de uma situação e como cada uma se relaciona com a flexão verbal ou com expressões modais:

\begin{tabular}{|l|l|l|}
\hline Realidade Factual & Realidade Projetada & Realidade Potencial \\
\hline $\begin{array}{l}\text { Uso de flexões no passado e } \\
\text { no presente em sentenças } \\
\text { assertivas. }\end{array}$ & $\begin{array}{l}\text { Sinalizada pelo uso de } \\
\text { formas no futuro. }\end{array}$ & $\begin{array}{l}\text { Sinalizada pelo uso de verbos } \\
\text { modais e do modo subjuntivo. }\end{array}$ \\
\hline
\end{tabular}

QUADRO 1 - Diferenças entre Realidade Factual, Realidade Projetada e Realidade Potencial Fonte: Autora. 


\section{REVISTA DA ABRALIN}

Tendo em vista o que foi dito, Abraçado finaliza sua fala destacando Langacker (1991), que propõe que quando nos deparamos com uma dada situação, conferimos a ela um estatuto de realidade, localizamos sua ocorrência no tempo, além de construir nossa perspectiva de tal situação.

Através do que foi exposto, Abraçado pôde oferecer uma amostra da dimensão e da diversidade verificada no campo dos estudos cognitivistas, mostrando a complexidade da relação dialética entre tempo e realidade. Os exemplos empregados na apresentação, colhidos de jornais, deixam clara a necessária união entre teoria e prática, além de conferirem didática à exposição. Destaca-se que a importância que se inscreve na fala de Abraçado é imensa: a exposição contribui ao oportunizar visibilidade para o campo, além de possibilitar a discussão do assunto com um grande número de pessoas, dada a amplitude do evento e seu acesso democrático.

\section{REFERÊNCIAS}

ABORDAGEM cognitivista do tempo: o tempo e a concepção da realidade. Conferência apresentada por Jussara Abraçado [s.l., s.n.], 2020. 1 vídeo (59min 00s). Publicado pelo canal da Associação Brasileira de Linguística. Disponível em: https://www.youtube.com/watch?v=gdgpIs3UWGg\&t=526s. Acesso em: 09 jul. 2020.

ABRAÇADO, Jussara. O tempo, o tempo linguístico e o tempo verbal: propriedades e relações. São Paulo: Contexto, 2020.

LANGACKER, Ronald W. Foundation of cognitive grammar: V II. Descriptive Application. Stanford: Stanford University Press, 1991.

SILVA, Augusto Soares da. O significado na Linguagem e na Mente: Uma Introdução à Semântica. Braga: Universidade Católica Portuguesa. No prelo.

SILVA, Leosmar Aparecido da. Leituras sobre conceptualização linguística e corporeidade no dialeto goiano. In: SIMPÓSIO INTERNACIONAL DE ENSINO DE LÍNGUA PORTUGUESA, 2012, Uberlândia. Anais do Simpósio Internacional de Ensino De Língua Portuguesa. Uberlândia: EDUFU, 2012. 